\title{
A Prospective Study of Single Breath Vital Capacity Inhalation Induction with High Concentration of Sevoflurane (Sbvc-Hc) for LMA Insertion in Adults for Short Surgical Cases
}

\author{
Kailash Prabhudev ${ }^{1}$, Naveen Kumar K ${ }^{2}$ \\ ${ }^{1}$ Assistant Professor, Department of Anaesthesia and Critical Care, MVJ Medical College and Research Hospital, Hoskote, Karnataka, India, ${ }^{2} \mathrm{Junior}$ \\ Resident, Department of Anaesthesia and Critical Care, MVJ Medical College and Research Hospital, Hoskote, Karnataka, India.
}

\section{Abstract}

Background: Sevoflurane is a new volatile anesthetic agent with rapid induction and recovery. A randomized study was carried to access conditions for LMA insertion using Sevoflurane in 25 ASA I \& II patients undergoing short duration surgeries. Subjects and Methods: This prospective study was conducted at Department of Anesthesiology and Critical Care, SVS Medical College and Hospital, Mahabubnagar, Telangana, India. After obtaining the institutional ethics committee and written informed consent from the patients, 25 subjects of either sex were included in this study. Age of the subjects was 18 to 60 years. Patients received injection Fentanyl $1-2 \mathrm{mcg} / \mathrm{kg}$ prior to induction. All patients were pre-oxygenated for 3 min with $100 \%$ oxygen using a fresh gas flow of $81 / \mathrm{min}$. All patients received inhalational induction with $8 \%$ Sevoflurane and $\mathrm{O} 2$ flow at $8 \mathrm{~L} / \mathrm{min}$ with single vital capacity breathe technique. Loss of verbal contact was considered as the desired endpoint for induction, which was assessed by the response to calling out the patient's name. Then the time of loss of eyelash reflex and jaw relaxation was assessed by anesthesiologist. After adequate jaw relaxation, LMA insertion was attempted. Results: The mean loss of verbal contact was $65.40 \pm 9.67$ second, while the mean for time for loss of eyelash reflex and jaw relaxation were found to be $81.20 \pm 9.39$ seconds and $103.20 \pm 12.07$ seconds respectively. The mean time for LMA insertion was $122.00 \pm 15.61$ and the mean attempts for successful LMA insertion was $1.12 \pm 0.33$. LMA insertion was easy in 23 cases as against difficult in 2 cases. In 2 cases transient cough and biting were recorded. LMA insertion was excellent and satisfactory in 88.0 and 12 percent. However, the mean heart rate at 5 minute after induction showed a significant fall at 5 minutes after induction. The mean values of SBP, DBP and MAP did not differ significantly at pre and induction. However, a significant decrease in SBP was noticed at 1,2 and at 5 minutes. Conclusion: Sevoflurane is an smooth inhalation anesthesia with rapid onset with adequate jaw relaxation for insertion of LMA in Adults for short duration surgeries. Sevoflurane has got good hemodynamic profile with lesser complications owing to choice of inhalation agent for insertion of LMA.

Keywords: Laryngeal mask airway, Sevoflurane.

Corresponding Author: Dr. Kailash Prabhudev, Assistant Professor, Department of Anaesthesia and Critical Care, MVJ Medical College and Research Hospital, Hoskote, Bangalore, Karnataka.

Email: kailashpdev@gmail.com

Received: February 2020

Accepted: February 2020

\section{Introduction}

Insertion of the laryngeal mask airway (LMA) under deep inhaled anesthesia alone is not commonly performed in adult patients. A popular method of providing anesthesia for LMA insertion is with the use of IV propofol, which has the advantages of inducing anesthesia rapidly and depressing upper airway reflexes. ${ }^{[1]}$ However, propofol is by no means ideal, as it has been associated with several adverse effects including hypotension, apnea, and pain on injection. ${ }^{[2]}$ Recently, single vital capacity breath (VCB) inhaled induction of anesthesia with sevoflurane has been used as an alternative to IV induction in adults. This method is rapid, with little excitatory phenomena, high patient acceptance, and good hemodynamic stability. ${ }^{[3]}$ Rapid insertion of the LMA after VCB induction may allow the use of sevoflurane as a single drug for the induction and maintenance of anesthesia, which would ease the transition period and lead to cost-savings. ${ }^{[4]}$ Therefore, the present study accessed the quality, and speed of LMA insertion, hemodynamic profiles and complications in adult patients after sevoflurane VCB induction.

\section{Subjects and Methods}

This study was conducted in Department of Anesthesia and Critical Care, SVS Medical College and Hospital, Mahabubnagar, Telangana. After institutional ethical committee approval and written informed consent from the study subjects, 25 patients of both sexes were selected for this study from department of Obstetrics and Gynecology, Orthopedics, Surgery and Urology. The age of the patients 
is 18 to $60 \mathrm{yrs}$, belonging to American Society of Anesthesiologists physical status I and II, who were scheduled for elective short duration surgical procedures. Patients <18 years, >60 years, ASA III, IV, morbidly obese, patients requiring endotracheal intubation and major procedures requiring muscle relaxation were excluded from the study. All patients underwent pre anesthetic checkup and routine investigations were carried out. Patients were premeditated with tab. Ranitidine 15Onda, Tab Alprazolam $0.5 \mathrm{mg}$ and Tab Ondansetron $4 \mathrm{mg}$ night before surgery and on the morning of the day of surgery with sips of water. On arrival to operation room and 18G IV line was secured, basal vital parameters were recorded. Patients received injection Fentanyl $1-2 \mathrm{mcg} / \mathrm{kg}$ prior to induction. All patients were pre-oxygenated for 3 min with $100 \%$ oxygen using a fresh gas flow of $81 / \mathrm{min}$. All the received inhalational induction was started with $8 \%$ Sevoflurane and $\mathrm{O} 2$ flow at $8 \mathrm{~L} / \mathrm{min}$ with single vital capacity breathe technique. The point of introduction of sevoflurane $8 \%$ was considered as starting point of induction. Loss of verbal contact was considered as the desired endpoint for induction in this technique, which was assessed by the response to calling out the patient's name. Then the time of loss of eyelash reflex and jaw relaxation was assessed by anesthesiologist. If jaw relaxation was not adequate, it was reassessed after every 15 seconds. Once jaw relaxation was adequate, LMA insertion was attempted.

\section{The following data were recorded}

a) Time taken from start of induction to loss of eyelash reflex, jaw relaxation and successful LMA insertion.

b) Number of attempts of LMA insertion.

c) Hemodynamic parameters, namely, heart rate, systolic blood pressure (SBP), diastolic blood pressure (DBP) and mean arterial blood pressure (MAP) were recorded and assessed before and after the insertion of LMA, at the end of 1,2 and 5 minute after the insertion. The conditions of insertion of LMA were graded by an observer on a threepoint scale using 6 variables, e.g., jaw relaxation, ease of LMA insertion, coughing, gagging, laryngospasm, and patient movement. Overall conditions for insertion of LMA were assessed as excellent, satisfactory or poor on the basis of total score obtained by summing up the individual scores of each component. Maximum score of 18 (Excellent: 18, Satisfactory: 16-17, Poor: $\leq 16$ ) is attained.

\section{Statistical analysis}

The Excel and SPSS (SPSS Inc., Chicago) software packages were used for data entry and analysis. The results were expressed as mean \pm SD for continuous variables and categorical variables were expressed as percentages.

\section{Results}

In this study, 25 patients were included; among them 9 were males and 16 were females as shown in [Table 1]. In the present study, the mean loss of verbal contact was $65.40 \pm 9.67$ second, while the mean for time for loss of eyelash reflex and jaw relaxation were found to be
$81.20 \pm 9.39$ and $103.20 \pm 12.07$ seconds respectively. The mean time for LMA insertion was $122.00 \pm 15.61$ and the mean attempts for successful LMA insertion was $1.12 \pm 0.33$ as depicted in [Table 2]. The heart rate at baseline, at the time of induction and at 1 minute after induction showed no significant variations. However, the mean heart rate at 5 minute after induction showed a significant fall at 5 minutes after induction. The mean SBP did not differ significantly at pre and induction. However, a significant decrease in SBP was noticed at 1 and 2 minutes and at 5 minutes. The mean values of DBP and MAP showed similar trend as that of SBP as shown in [Table 3].

Table 1: Demographic characteristics of the study subjects

\begin{tabular}{|l|l|}
\hline Variables & Number of patients (n=25) (\%) \\
\hline Age (years) & $39.3 \pm 11.7 *$ \\
\hline Male & $9(36.0 \%)$ \\
\hline Female & $16(64.0 \%)$ \\
\hline Patients in various departments \\
\hline Obstetrics and Gynecology & $9(36.0 \%)$ \\
\hline Orthopedics & $3(12.0 \%)$ \\
\hline Surgery & $6(24.0 \%)$ \\
\hline Urology & $7(28.0 \%)$ \\
\hline * Mean \pm SD
\end{tabular}

Table 2: Time for laryngeal mask airway insertion (LMA) in seconds (sevoflurane)

\begin{tabular}{|l|l|}
\hline Variables & $\begin{array}{l}\text { Patients }(\mathbf{n}=25) \\
\text { Mean } \pm \text { SD (seconds) }\end{array}$ \\
\hline Loss of verbal contact & $65.40 \pm 9.67$ \\
\hline Loss of eyelash reflex & $81.20 \pm 9.39$ \\
\hline Jaw relaxation & $103.20 \pm 12.07$ \\
\hline LMA insertion & $122.00 \pm 15.61$ \\
\hline $\begin{array}{l}\text { Number of attempts for successful } \\
\text { LMA insertion }\end{array}$ & $1.12 \pm 0.33$ \\
\hline
\end{tabular}

Table 3: Trends in hemodynamic parameters sevoflurane

\begin{tabular}{|c|c|c|c|c|c|}
\hline & Pre & $\begin{array}{l}\text { Inductio } \\
\text { n }\end{array}$ & $1 \mathrm{~min}$ & $2 \mathrm{~min}$ & $5 \mathrm{~min}$ \\
\hline $\begin{array}{l}\text { Heart } \\
\text { rate } \\
(\mathrm{bpm})\end{array}$ & $\begin{array}{l}84.96 \pm 7 . \\
71 \mathrm{a}\end{array}$ & $\begin{array}{l}84.48 \pm 8.2 \\
0 \mathrm{a}\end{array}$ & $\begin{array}{l}86.48 \pm 10 . \\
74 \mathrm{a}\end{array}$ & $\begin{array}{l}82.68 \pm 1 \\
1.76 \mathrm{a}\end{array}$ & $\begin{array}{l}79.84 \pm 9.9 \\
8 \mathrm{a}\end{array}$ \\
\hline $\begin{array}{l}\text { SBP } \\
(\mathrm{mmHg})\end{array}$ & $\begin{array}{l}128.88 \pm \\
8.15 \mathrm{a}\end{array}$ & $\begin{array}{l}125.36 \pm 1 \\
2.01 \mathrm{a}\end{array}$ & $\begin{array}{l}118.36 \pm 11 \\
.06 \mathrm{~b}\end{array}$ & $\begin{array}{l}112.56 \pm \\
9.01 \mathrm{~b}\end{array}$ & $\begin{array}{l}104.44 \pm 1 \\
1.45 \mathrm{~b}\end{array}$ \\
\hline $\begin{array}{l}\mathrm{DBP}(\mathrm{mm} \\
\mathrm{Hg})\end{array}$ & $\begin{array}{l}81.44 \pm 8 . \\
25 \mathrm{a}\end{array}$ & $\begin{array}{l}80.48 \pm 8.8 \\
2 \mathrm{a}\end{array}$ & $\begin{array}{l}74.00 \pm 7.6 \\
4 \mathrm{~b}\end{array}$ & $\begin{array}{l}71.12 \pm 7 \\
64 \mathrm{~b}\end{array}$ & $\begin{array}{l}69.44 \pm 8.7 \\
3 \mathrm{~b}\end{array}$ \\
\hline $\begin{array}{l}\text { MAP } \\
(\mathrm{mmHg})\end{array}$ & $\begin{array}{l}97.25 \pm 7 . \\
11 \mathrm{a}\end{array}$ & $\begin{array}{l}93.44 \pm 8.4 \\
0 \mathrm{~b}\end{array}$ & $\begin{array}{l}88.79 \pm 7.3 \\
8 \mathrm{c} \\
\end{array}$ & $\begin{array}{l}84.93 \pm 7 . \\
72 \mathrm{~d}\end{array}$ & $\begin{array}{l}82.41 \pm 7.2 \\
2 \mathrm{~d} \\
\end{array}$ \\
\hline \multicolumn{6}{|c|}{$\begin{array}{l}\text { Note: Means bearing different superscripts differ significantly with each } \\
\text { other }\end{array}$} \\
\hline
\end{tabular}

Table 4: Complications during induction of anesthesia and laryngeal mask airway insertion

\begin{tabular}{|l|l|l|l|}
\hline Parameter & Grade & Description & Groups \\
\hline \multirow{3}{*}{ Jaw relaxation } & 3 & Full & 23 \\
\cline { 2 - 4 } & 2 & Partial & 02 \\
\hline \multirow{2}{*}{$\begin{array}{l}\text { Ease of LMA } \\
\text { insertion }\end{array}$} & 3 & Easy & 23 \\
\hline \multirow{2}{*}{ Coughing } & 2 & Difficult & 02 \\
\hline \multirow{2}{*}{ Biting } & 3 & Nil & 23 \\
\cline { 2 - 4 } & 2 & Transient & 02 \\
\hline Gagging & 3 & Nil & 23 \\
\hline Laryngospasm & 2 & Transient & 02 \\
\hline
\end{tabular}


Table 5: Grading of conditions for LMA insertion Sevoflurane

\begin{tabular}{|l|l|l|}
\hline 16.00 & 17.00 & 18.00 \\
\hline $2(8.0 \%)$ & $1(4.0 \%)$ & $22(88.0 \%)$ \\
\hline
\end{tabular}

Excellent: 18 score, Satisfactory: 16-17 score, Poor: $\leq 16$

The distribution of complications during induction of anesthesia and laryngeal mask airway insertion revealed full Jaw relaxation in 23 cases while in 2 cases partial. LMA insertion was easy in 23 cases as against difficult in 2 cases. Coughing and biting was not observed in 23 cases and transient coughing and biting was observed in 2 cases. None of the patients evidenced Gaging or Laryngospasm as illustrated in [Table 4]. In the present study, $22(88 \%)$ patients had excellent conditions for LMA insertion, while 3 patients $(12 \%)$ had satisfactory condition for LMA insertion when grading was done using 18 point score as illustrated in [Table 5].

\section{Discussion}

Satisfactory insertion of LMA after induction of anesthesia requires a sufficient depth of anesthesia. ${ }^{[5]}$ Propofol is a common IV anesthetic agent used for LMA insertion because of its greater depressant effect on airway reflxes. ${ }^{[6]}$ Sevoflurane is suitable for inhalational induction technique even in high concentrations because of its low blood gas solubility and minimal respiratory irritant effect. The vital capacity induction technique with sevoflurane was used to make the technique similar to that of IV bolus injection of propofol. $^{[7]}$

\section{Time Taken for LMA Insertion}

In the present study, mean time taken from induction to successful laryngeal mask insertion was $122.00 \pm 15.61$ with sevoflurane. Molloy et al. (1999) reported that the mean time for successful LMA insertion with sevoflurane has been reported to be 2.2 min. ${ }^{[8]}$ In a study by Ti et al. (1999) reported that $127 \pm 35$ seconds. ${ }^{[9]}$ In a study by Ganatra SB et al. (2002) reported that the Mean \pm SD time taken from induction to successful laryngeal mask insertion was significantly shorter with propofol $(68.70 \pm 22.60 \mathrm{~s})$ compared with sevoflurane $(149.83 \pm 55.25 \mathrm{~s})$. Excellent or satisfactory conditions were observed in 30 (100\%) patients in the propofol group and in 29 (96.66\%) in the sevoflurane group. Systolic and diastolic arterial pressures were significantly lower in the propofol group. Concluded that haemodynamic stability was better with sevofluranefentanyl. The propofol-fentanyl combination was more costeffective. ${ }^{[10]}$

Shao $\mathrm{G}$ and Zhang G, compared the efficacies of sevoflurane and propofol inductions for laryngeal mask airway (LMA) insertion in elderly patients. Reported that LMA was inserted most, less or least rapidly with propofol $(89 \pm 28 \mathrm{~s})$, sevoflurane $8 \%$ using the VCB $(163 \pm 34$ s) or TVB $(205 \pm$ 44 s) techniques, respectively. They concluded that Sevoflurane $8 \%$ using the TVB technique provides a smoother induction with a stable hemodynamic profile, less apnea and technical demand, but requiring longer time for LMA insertion in unpremedicated elderly patients. ${ }^{[1]}$ ElRadaideh and Al-Ghazo et al. (2007) and Dwivedi et al. (2015) reported that $122.2 \pm 33.3$ seconds with the single
VCB and $116.3 \pm 7.06$ seconds respectively. ${ }^{[12,13]}$

In the present study, mean time taken from induction to successful laryngeal mask insertion as observed is $122.00 \pm 15.61$ seconds. This findings were supported by the study done by El-Radaideh and Al-Ghazo et al. (2007) who achieved mean value of $122.2 \pm 33.3$ seconds for successful LMA insertion with sevoflurane. ${ }^{[12]}$ In a study by Dwivedi et al. (2015) reported that the mean Jaw relaxation time of $100.1 \pm 7.4$ seconds, which is almost closer to $122.00 \pm 15.61$ seconds obtained in the present study.

Ti et al. (1999), ${ }^{[9]}$ and Priya et al. (2002), ${ }^{[14]}$ who reported that propofol is better than sevoflurane for LMA insertion using the loss of eyelash reflex as the end point of induction probably due to better jaw relaxation and concluded that prolonged jaw tightness after sevoflurane induction of anesthesia may delay LMA insertion. According to them, propofol is known to have a relaxant effect on jaw muscles, whereas inhaled anesthetics may cause increased tone and spatisticity. Therefore for a similar depth of anesthesia, there may be greater jaw relaxation with propofol. Muzi et al. (1996), ${ }^{[14]}$ in their study reported jaw tightness after sevoflurane anesthetic induction, which resulted in failure to insert the LMA in several patients

\section{Analysis of Condition for LMA Insertion}

In this study, inadequate jaw relaxation was found in 02 patients in sevoflurane group. In the same patients, ease of LMA insertion was difficult requiring second attempt and LMA inserted in the second attempt, probably due to inadequate jaw relaxation. The mean number of attempts taken for LMA insertion was $1.12 \pm 0.33$ which is comparable to $1.16 \pm 0.37$ obtained by Dwivedi et al. (2015). ${ }^{[13]}$

In the present study, the overall condition of LMA insertion was graded as excellent (score of 18$)$ in $22(88.0 \%)$ patients, one patient $(4.0 \%)$ had satisfactory condition (score of 17 ) and $2(8.0 \%)$ patients had score of 16 with LMA insertion grading as poor. In Similar study 30 patients with sevoflurane, Dwivedi et al. (2015) [13] reported the overall condition of LMA insertion in 24,2 and 4 patients respectively had excellent, satisfactory and poor grade

In a similar study conducted by Priya et al. (2002), ${ }^{[14]}$ features like coughing, gagging, and patient movements did not reach statistical significance. Priya et al. (2002) in their study noted that jaw relaxation with propofol was much better. With sevoflurane, they noted that induction took a longer time because sevoflurane has less relaxation properties when compared to propofol. ${ }^{[14]} \mathrm{Ti}$ et al. (1999) in their study found that more attempts at insertion of LMA were required in patients in sevoflurane group; they suggested that this was primarily because of incidence of initially impossible mouth opening. ${ }^{[9]}$

Philip et al. (1999) in their study noted more airway-related events (cough, hiccough) in the sevoflurane group .The airway related incidents in the present study was meager with sevoflurane but of no of significance. This cannot be commented as the study group is very small. Other features like coughing, gagging a, patient movements, and laryngospasm did not reach statistical significance in our study. ${ }^{[16]}$

The hemodynamic responses were stable and clinically accepted. In our study, the heart rate at baseline, at the time 
of induction and at 1 minute after induction showed no significant variations. However, the mean heart rate at 5 minute after induction showed a significant fall at 5 minutes after induction. The mean SBP did not differ significantly at pre and induction. However, a significant decrease in SBP was noticed at 1 and 2 minutes and at 5 minutes the mean SBP was significantly lower as compared to 1 and 2 minutes. The mean values of DAP and MAP showed similar trend as that of SBP. This was comparable to the study by Ahmeduddin Soomro et al. (2013). ${ }^{[17]}$

\section{Conclusion}

Sevoflurane is an smooth inhalation anesthesia with rapid onset with adequate jaw relaxation for insertion of LMA in Adults for short duration surgeries. Sevoflurane has got good hemodynamic profile with lesser complications owing to choice of inhalation agent for insertion of LMA.

\section{Acknowledgement:}

We would like to thank the authorities of SVS Medical College and Hospital, Mahabubnagar, Telangana for supporting this study.

\section{References}

1. Scanlon P, Carey M, Power M. Patient response to laryngeal mask insertion after induction of anesthesia with propofol or thiopentone. Can J Anaesth 1993; 40:816-8.

2. Sebel PS, Lowdon JD. Propofol: a new intravenous anesthetic. Anesthesiology 1989;71:260 -77.

3. Yurino $\mathbf{M}$, Kimura $\mathrm{H}$. Induction of anesthesia with sevoflurane, nitrous oxide, and oxygen: a comparison of spontaneous ventilation and vital capacity rapid inhalation induction (VCRII) techniques. Anesth Analg
1993;76:598-601.

4. Thwaites A, Edmends S, Smith I. Inhalation induction with sevoflurane: a double-blind comparison with propofol. Br J Anaesth 1997;78:356-61.

5. Ferson DZ, Brimacombe J, Brain AI, Verghese C. The intubating laryngeal mask airway. Int Anesthesiol Clin 1998;36:183-209.

6. Brown GW, Patel N, Ellis FR. Comparison of propofol and thiopentone for laryngeal mask insertion. Anaesthesia 1991;46:771-2.

7. Baker CE, Smith I. Sevoflurane: A comparison between vital capacity and tidal breathing techniques for the induction of anesthesia and laryngeal mask airway placement. Anaesthesia 1999; 54:841-4.

8. Molloy ME, Buggy DJ, Scanlon P. Propofol or sevoflurane for laryngeal mask airway insertion. Can J Anaesth 1999;46(4):322-6.

9. Ti LK, Chow MY, Lee TL. Comparison of sevoflurane with propofol for laryngeal mask airway insertion in adults. Anesth Analg 1999;88(4):90812 .

10. Ganatra SB, D'Mello J, Butani M, Jhamnani P. Conditions for insertion of the laryngeal mask airway: comparisons between sevoflurane and propofol using fentanyl as a co-induction agent. A pilot study. Eur J Anaesthesiol 2002; 19(5):371-5.

11. Shao G and, Zhang G. Comparison of propofol and sevoflurane for laryngeal mask airway insertion in elderly patients South Med J 2007; 100(4):360-5.

12. El-Radaideh KM and Al-Ghazo MA. Single breath vital capacity induction of anesthesia with $8 \%$ sevoflurane versus intravenous propofol for laryngeal tube insertion in adults. Saudi Med J 2007; 28(1):36-40.

13. Dwivedi R, Dwivedi S, Chourasia HK. A Comparative Study of Sevoflurane and Propofol for Laryngeal Mask Airway Insertion in Adults. Int J Sci Stud 2015; 3(1):67-71.

14. Priya V, Divatia JV, Dasgupta D. Comparison of propofol versus sevoflurane for laryngeal mask airway insertion. Indian J Anesthesia 2002;46:31-4

15. Muzi M, Robinson BJ, Ebert TJ, O’Brien TJ. Induction of anesthesia and tracheal intubation with sevofl urane in adults. Anesthesiology 1996;85:536-43.

16. Philip BK, Lombard LL, Roaf ER, Drager LR, Calalang I, Philip JH. Comparison of vital capacity induction with sevofl urane to intravenous induction with propofol for adult ambulatory anesthesia. Anesth Analg 1999; 89:623-7.

17. Ahmeduddin Soomro, Amjad Ali, Sadqa Aftab. Comparison of Propofol and Sevoflurane for Laryngeal Mask Airway Insertion. J Rawalpindi Med College 2013; 17(2):268-270.

Copyright: () the author(s), 2020. It is an open-access article distributed under the terms of the Creative Commons Attribution License (CC BY 4.0), which permits authors to retain ownership of the copyright for their content, and allow anyone to download, reuse, reprint, modify, distribute and/or copy the content as long as the original authors and source are cited.

How to cite this article: Prabhudev K, Kumar KN. A Prospective Study of Single Breath Vital Capacity Inhalation Induction with High Concentration of Sevoflanane (Sbvc-Hc) for LMA Insertion in Adults for Short Surgical Cases. Acad. Anesthesiol. Int. 2020;5(1):30-33.

DOI: dx.doi.org/10.21276/aan.2020.5.1.6

Source of Support: Nil, Conflict of Interest: None declared. 